\title{
Poverty, time, and place: variation in excess mortality across selected US populations, 1980-1990
}

\author{
Arline T Geronimus, John Bound, Timothy A Waidmann
}

\begin{abstract}
Study objective-To describe variation in levels and causes of excess mortality and temporal mortality change among young and middle aged adults in a regionally diverse set of poor local populations in the USA.
\end{abstract}

Design-Using standard demographic techniques, death certificate and census data were analysed to make sex specific population level estimates of 1980 and 1990 death rates for residents of selected areas of concentrated poverty. For comparison, data for whites and blacks nationwide were analysed.

Setting-African American communities in Harlem, Central City Detroit, Chicago's south side, the Louisiana Delta, the Black Belt region of Alabama, and Eastern North Carolina. Non-Hispanic white communities in Cleveland, Detroit, Appalachian Kentucky, South Central Louisiana, Northeastern Alabama, and Western North Carolina.

Participants-All black residents or all white residents of each specific community and in the nation, 1979-1981 and 1989-1991.

Main results-Substantial variability exists in levels, trends, and causes of excess mortality in poor populations across localities. African American residents of urban/northern communities suffer extremely high and growing rates of excess mortality. Rural residents exhibit an important mortality advantage that widens over the decade. Homicide deaths contribute little to the rise in excess mortality, nor do AIDS deaths contribute outside of specific localities. Deaths attributable to circulatory disease are the leading cause of excess mortality in most locations. Conclusions-Important differences exist among persistently impoverished populations in the degree to which their poverty translates into excess mortality. Social epidemiological inquiry and health promotion initiatives should be attentive to local conditions. The severely disadvantageous mortality profiles experienced by urban African Americans relative to the rural poor and to national averages call for understanding.

(F Epidemiol Community Health 1999;53:325-334)

Professor A T Geronimus,

1420 Washington Heights,

Ann Arbor, MI 48109-2029,

USA.

Accepted for publication 13 November 1998
Adult health during the reproductive and working ages is important and reflects the well being of communities. The health of reproductive age women directly influences the health of the next generation. ${ }^{12}$ Working age adults play critical roles as economic providers and caretakers in families. In low income African American communities, adults in this age group often face multiple obligations in supporting family economies and caretaking systems. ${ }^{34}$ Yet, national studies indicate that the disproportionately high rates of disease and disorders suffered by African American or low income people are pronounced for young through middle aged adults..$^{5-8}$ Excess morbidity and mortality in this age group are greatest among African Americans in poverty. ${ }^{9-11}$ High levels of early health deterioration in this population may be both cause and consequence of expanded caretaking obligations among the relatively healthy. ${ }^{512}$

Excess mortality rates in poor populations, themselves, may vary with geographical differences. In particular, rural Americans in the first half of the 20th century enjoyed longer life expectancies than urban dwellers. ${ }^{13}{ }^{14}$ Evidence based on more recent cohorts is mixed, ${ }^{15-18}$ and suggests little, if any, mortality advantage for rural compared with urban dwellers in young and middle adulthood. ${ }^{8}{ }^{19}$ However, with some resurgence of infectious disease entities as important causes of death in urban areas and general perceptions of central cities as having become more dangerous and unhealthy in the most recent decades, ${ }^{20}{ }^{21}$ the fortunes of rural dwellers, even those in poverty, may have again increased relative to their urban counterparts. In addition, important interactions between race, poverty, and rural/urban residence may exist, but be unobserved in analyses of national data sets where only main effects of residence are estimated as a product of averaging across rural compared with urban dwellers.

In an earlier study we compared the mortality experience of young and middle aged adults across a select group of white and African American local areas in $1990 .{ }^{10}$ Relative to whites nationwide, levels of excess mortality varied across the local populations. The findings hinted that members of urban poor populations might be at substantially higher risk of early death than members of rural poor populations.

We extend this work $^{10}$ by describing the mortality experience of an expanded set of impoverished populations that includes a larger number of rural populations and covers two time periods. By analysing data for 1980 and 1990, we shed light on the dynamics of temporal mortality level change in highly impoverished 
Table 1 Summary data on the study areas, 1980 and 1990*

\begin{tabular}{|c|c|c|c|c|}
\hline Area & Year & $\begin{array}{l}\text { Number of } \\
\text { inhabitants }\end{array}$ & $\begin{array}{l}\text { Mean family } \\
\text { income (1990 \$) }\end{array}$ & $\begin{array}{l}\text { Families below the } \\
\text { poverty level }(\%)\end{array}$ \\
\hline \multicolumn{5}{|l|}{ US population } \\
\hline \multirow[t]{2}{*}{ Total } & 1980 & 226545805 & 39441 & 9.6 \\
\hline & 1990 & 248709873 & 43803 & 10.0 \\
\hline \multirow[t]{2}{*}{ Whites } & 1980 & 189035012 & 41276 & 7.0 \\
\hline & 1990 & 199827064 & 46330 & 7.0 \\
\hline \multirow[t]{2}{*}{ Blacks } & 1980 & 26482349 & 26788 & 26.5 \\
\hline & 1990 & 29930524 & 28659 & 26.3 \\
\hline \multicolumn{5}{|l|}{ Blacks } \\
\hline \multirow[t]{2}{*}{ Harlem } & 1980 & 115191 & 20530 & 33.4 \\
\hline & 1990 & 101697 & 24174 & 33.1 \\
\hline \multirow[t]{2}{*}{ Central City Detroit } & 1980 & 135362 & 22265 & 38.5 \\
\hline & 1990 & 98833 & 19841 & 44.3 \\
\hline \multirow[t]{2}{*}{ Southside Chicago } & 1980 & 144634 & 19348 & 46.7 \\
\hline & 1990 & 101895 & 16651 & 58.2 \\
\hline \multirow{2}{*}{ Delta Louisiana } & 1980 & 107371 & 16704 & 48.0 \\
\hline & 1990 & 101928 & 15524 & 48.1 \\
\hline \multirow[t]{2}{*}{ Black Belt Alabama } & 1980 & 99684 & 17666 & 45.1 \\
\hline & 1990 & 93695 & 17222 & 48.7 \\
\hline \multirow[t]{2}{*}{ East North Carolina } & 1980 & 99161 & 20928 & 34.9 \\
\hline & 1990 & 107573 & 20802 & 32.8 \\
\hline \multicolumn{5}{|l|}{ Whites } \\
\hline \multirow[t]{2}{*}{ Cleveland } & 1980 & 114720 & 30261 & 16.4 \\
\hline & 1990 & 104207 & 27714 & 21.4 \\
\hline \multirow[t]{2}{*}{ Detroit } & 1980 & 200938 & 35682 & 10.9 \\
\hline & 1990 & 126752 & 29334 & 22.0 \\
\hline \multirow[t]{2}{*}{ Appalachian Kentucky } & 1980 & 113078 & 21828 & 32.9 \\
\hline & 1990 & 109794 & 21628 & 34.6 \\
\hline \multirow[t]{2}{*}{ South Central Louisiana } & 1980 & 88123 & 35926 & 12.8 \\
\hline & 1990 & 87682 & 29274 & 18.9 \\
\hline \multirow[t]{2}{*}{ Northeast Alabama } & 1980 & 165972 & 29217 & 14.3 \\
\hline & 1990 & 167037 & 30480 & 13.6 \\
\hline \multirow[t]{2}{*}{ West North Carolina } & 1980 & 161521 & 28098 & 14.5 \\
\hline & 1990 & 167524 & 30675 & 12.0 \\
\hline
\end{tabular}

${ }^{\star}$ Data are from the 1980 and 1990 US censuses. $†$ Numbers shown refer to only black residents or only white residents, depending on the area studied. $¥$ The poverty levels were those defined by the Bureau of the Census. wise, among whites, rural/southern populations tended to be better off economically than urban/northern ones.

The local areas were selected based on comparatively low race specific mean family income and relatively high percentages of families with incomes below the poverty threshold. They were not randomly selected areas of concentrated poverty, but were chosen to reflect racial and geographical diversity given data constraints. Each population was sufficiently large to perform fine grained mortality analyses among young through middle aged adults. For African Americans, this size requirement limited us to major cities or to southern rural areas. As the death certificate data were provided by state vital statistics offices, we were limited to states that included geographical identifiers in their files and, for areas with large Hispanic populations, that separated nonHispanic from Hispanic whites. (For example, we could not study Chicago whites for this reason.)

As data permitted we included local populations from our earlier 1990 analysis. ${ }^{10}$ We were able to maintain six of the eight original local populations. All of these populations were also quite poor in 1980, with the exception of the white Detroit population. In 1980, that population was less advantaged than whites nationwide $(11 \%$ of families had incomes below the poverty threshold, compared with $7 \%$ for whites nationwide), but it was better off than any other study population and far better off than it became a decade later. Other local populations that experienced smaller, but noticeable, increases in their concentration of poverty were blacks in Chicago (from $47 \%$ in 1980 to $58 \%$ in 1990) and Detroit (from 39\% to $44 \%)$, and whites in Cleveland $(16 \%$ to $21 \%$ ) and Louisiana (13\% to $19 \%$ ).

\section{ESTIMATION PROCEDURES}

We combined population specific death certificate information for 1979-1981 and 19891991 with age stratified counts of men and women in each population taken from the 1980 and 1990 census, respectively, to calculate age and sex specific death rates, overall and resulting from specific causes of interest. To mitigate biases because of census undercounting, we adjusted population counts using national undercount adjustments.

We computed several measures of mortality. We computed summary measures including age adjusted rate ratios (RRs) and age standardised annual excess death rates (EDRs). ${ }^{22}{ }^{23}$ To ensure that the reported measures are comparable across populations, our calculations constituted direct standardisation on the age distribution of the US white population by sex..$^{24}$ For each local population, we calculated the number of deaths that would be expected in the US white population if it faced the age and cause specific death rates of the local population. For the RRs, we divided expected by observed deaths in the US white population. We calculated the EDRs as $100000 \times$ (expected deaths-observed deaths) /US white population. 
Table 2 Measures of mortality among blacks and whites 15 to 64 years old in selected populations, according to sex, 1980 and 1990

\begin{tabular}{|c|c|c|c|c|c|c|c|c|}
\hline & Year & $\begin{array}{l}\text { Annual } \\
\text { death rate }\end{array}$ & $\begin{array}{l}\text { Total number } \\
\text { of deaths }\end{array}$ & $\begin{array}{l}\text { Age standardised annual } \\
\text { excess death rate }\end{array}$ & $\begin{array}{l}\text { Age adjusted rate ratio } \\
\text { ( } 95 \% \text { confidence intervals) }\end{array}$ & $p 45^{\star}$ & $p 65^{\star *}$ & YOLLt \\
\hline \multicolumn{9}{|l|}{ Total US male population } \\
\hline \multirow{2}{*}{ Blacks } & 1980 & 809 & 62093 & 332 & $1.70(1.68,1.71)$ & 0.89 & 0.60 & 5.59 \\
\hline & 1990 & 791 & 69439 & 374 & $1.90(1.88,1.91)$ & 0.88 & 0.62 & 5.78 \\
\hline \multirow[t]{2}{*}{ Whites } & 1980 & 477 & 312382 & 0 & $1.00(1.00,1.00)$ & 0.94 & 0.74 & 3.36 \\
\hline & 1990 & 417 & 282076 & 0 & $1.00(1.00,1.00)$ & 0.94 & 0.77 & 3.10 \\
\hline \multicolumn{9}{|l|}{ Black men } \\
\hline \multirow[t]{2}{*}{ Harlem } & 1980 & 1172 & 1541 & 695 & $2.46(2.33,2.58)$ & 0.80 & 0.50 & 8.92 \\
\hline & 1990 & 1713 & 1600 & 1296 & $4.11(3.91,4.31)$ & 0.71 & 0.37 & 11.33 \\
\hline \multirow[t]{2}{*}{ Central City Detroit } & 1980 & 1182 & 1577 & 705 & $2.48(2.35,2.60)$ & 0.82 & 0.48 & 8.47 \\
\hline & 1990 & 1163 & 1881 & 746 & $2.79(2.66,2.92)$ & 0.81 & 0.50 & 8.63 \\
\hline \multirow[t]{2}{*}{ South Side Chicago } & 1980 & 1432 & 1551 & 955 & $3.00(2.85,3.15)$ & 0.78 & 0.42 & 9.79 \\
\hline & 1990 & 1713 & 1222 & 1296 & $4.11(3.88,4.34)$ & 0.73 & 0.37 & 11.71 \\
\hline \multirow{2}{*}{ Delta Louisiana } & 1980 & 716 & 573 & 239 & $1.50(1.38,1.63)$ & 0.89 & 0.65 & 5.33 \\
\hline & 1990 & 808 & 583 & 391 & $1.94(1.78,2.10)$ & 0.91 & 0.60 & 5.40 \\
\hline \multirow{2}{*}{ Black Belt Alabama } & 1980 & 791 & 567 & 314 & $1.66(1.52,1.80)$ & 0.89 & 0.61 & 5.74 \\
\hline & 1990 & 755 & 516 & 338 & $1.81(1.65,1.97)$ & 0.91 & 0.63 & 5.39 \\
\hline \multirow[t]{2}{*}{ East North Carolina } & 1980 & 925 & 780 & 448 & $1.94(1.80,2.07)$ & 0.87 & 0.55 & 6.19 \\
\hline & 1990 & 906 & 781 & 489 & $2.17(2.02,2.33)$ & 0.89 & 0.57 & 6.13 \\
\hline \multicolumn{9}{|l|}{ White men } \\
\hline \multirow[t]{2}{*}{ Cleveland } & 1980 & 886 & 1005 & 409 & $1.86(1.74,1.97)$ & 0.88 & 0.58 & 6.28 \\
\hline & 1990 & 717 & 713 & 300 & $1.72(1.59,1.85)$ & 0.91 & 0.64 & 4.96 \\
\hline \multirow{2}{*}{ Detroit } & 1980 & 730 & 1595 & 253 & $1.53(1.45,1.61)$ & 0.91 & 0.63 & 5.19 \\
\hline & 1990 & 838 & 898 & 421 & $2.01(1.88,2.14)$ & 0.88 & 0.60 & 6.20 \\
\hline Appalachian Kentucky & 1980 & 762 & 767 & 285 & $1.60(1.48,1.71)$ & 0.90 & 0.63 & 5.44 \\
\hline & 1990 & 574 & 602 & 157 & $1.38(1.27,1.49)$ & 0.92 & 0.70 & 4.41 \\
\hline South Central Louisiana & 1980 & 589 & 491 & 112 & $1.24(1.13,1.34)$ & 0.92 & 0.70 & 4.40 \\
\hline & 1990 & 498 & 420 & 81 & $1.19(1.08,1.31)$ & 0.93 & 0.73 & 3.75 \\
\hline Northeast Alabama & 1980 & 542 & 873 & 65 & $1.14(1.06,1.21)$ & 0.93 & 0.71 & 3.88 \\
\hline & 1990 & 544 & 968 & 127 & $1.30(1.22,1.39)$ & 0.93 & 0.71 & 3.83 \\
\hline West North Carolina & 1980 & 504 & 808 & 27 & $1.06(0.98,1.13)$ & 0.94 & 0.73 & 3.69 \\
\hline & 1990 & 394 & 705 & -23 & $0.94(0.87,1.01)$ & 0.95 & 0.78 & 2.94 \\
\hline Total US female population & & & & & & & & \\
\hline Blacks & 1980 & 469 & 36487 & 217 & $1.86(1.84,1.88)$ & 0.95 & 0.75 & 3.06 \\
\hline & 1990 & 439 & 38825 & 214 & $1.95(1.93,1.97)$ & 0.95 & 0.77 & 2.89 \\
\hline Whites & 1980 & 252 & 164519 & 0 & $1.00(1.00,1.00)$ & 0.97 & 0.86 & 1.66 \\
\hline & 1990 & 225 & 149859 & 0 & $1.00(1.00,1.00)$ & 0.98 & 0.87 & 1.50 \\
\hline Black women & & & & & & & & \\
\hline Harlem & 1980 & 575 & 819 & 323 & $2.28(2.12,2.44)$ & 0.91 & 0.71 & 4.41 \\
\hline & 1990 & 759 & 803 & 534 & $3.38(3.15,3.61)$ & 0.87 & 0.65 & 5.56 \\
\hline Central City Detroit & 1980 & 629 & 807 & 377 & $2.50(2.33,2.67)$ & 0.90 & 0.69 & 4.69 \\
\hline & 1990 & 580 & 960 & 355 & $2.58(2.42,2.75)$ & 0.92 & 0.71 & 3.96 \\
\hline South Side Chicago & 1980 & 692 & 911 & 440 & $2.75(2.57,2.93)$ & 0.92 & 0.66 & 4.51 \\
\hline & 1990 & 794 & 720 & 569 & $3.53(3.27,3.79)$ & 0.88 & 0.63 & 5.49 \\
\hline Delta Louisiana & 1980 & 440 & 387 & 188 & $1.75(1.57,1.92)$ & 0.95 & 0.77 & 2.88 \\
\hline & 1990 & 473 & 372 & 249 & $2.11(1.89,2.32)$ & 0.94 & 0.75 & 3.11 \\
\hline Black Belt Alabama & 1980 & 416 & 352 & 164 & $1.65(1.48,1.82)$ & 0.94 & 0.78 & 3.05 \\
\hline & 1990 & 425 & 342 & 200 & $1.89(1.69,2.09)$ & 0.95 & 077 & 2.82 \\
\hline East North Carolina & 1980 & 438 & 402 & 186 & $1.74(1.57,1.91)$ & 0.94 & 0.76 & 3.04 \\
\hline & 1990 & 421 & 423 & 197 & $1.88(1.70,2.05)$ & 0.95 & 0.77 & 2.78 \\
\hline White women & & & & & & & & \\
\hline Cleveland & 1980 & 464 & 556 & 213 & $1.84(1.69,2.00)$ & 0.95 & 0.75 & 3.06 \\
\hline & 1990 & 371 & 360 & 147 & $1.65(1.48,1.82)$ & 0.96 & 0.80 & 2.37 \\
\hline Detroit & 1980 & 359 & 874 & 107 & $1.43(1.33,1.52)$ & 0.96 & 0.80 & 2.41 \\
\hline & 1990 & 428 & 440 & 203 & $1.90(1.73,2.08)$ & 0.95 & 0.77 & 2.83 \\
\hline Appalachian Kentucky & 1980 & 335 & 333 & 84 & $1.33(1.19,1.48)$ & 0.96 & 0.82 & 2.36 \\
\hline & 1990 & 312 & 321 & 87 & $1.39(1.23,1.54)$ & 0.97 & 0.82 & 2.15 \\
\hline South Central Louisiana & 1980 & 307 & 258 & 56 & $1.22(1.07,1.37)$ & 0.97 & 0.83 & 2.04 \\
\hline & 1990 & 256 & 214 & 32 & $1.14(0.99,1.29)$ & 0.96 & 0.86 & 1.89 \\
\hline Northeast Alabama & 1980 & 252 & 415 & 0 & $1.00(0.91,1.10)$ & 0.97 & 0.86 & 1.71 \\
\hline & 1990 & 283 & 508 & 58 & $1.26(1.15,1.37)$ & 0.96 & 0.84 & 2.04 \\
\hline West North Carolina & 1980 & 228 & 366 & -24 & $0.91(0.81,1.00)$ & 0.98 & 0.87 & 1.59 \\
\hline & 1990 & 192 & 339 & -32 & $0.86(0.76,0.95)$ & 0.98 & 0.89 & 1.33 \\
\hline
\end{tabular}

${ }^{\star} \mathrm{P} 45=$ probability of survival to age $45 .{ }^{\star}{ }^{\star} \mathrm{P} 65=$ probability of survival to age $65 .+$ YOLL $=$ average years of life lost between ages 15 and 65 .

We used Greville's method ${ }^{23} 24$ to derive probabilities of survival to various ages for 15 year olds living in the study populations. We also calculated average years of life lost between ages 15 and 65 in each population using standard life table methods. ${ }^{25}$ Using standard multidecrement life table techniques, ${ }^{25}{ }^{26}$ we estimated how many of the years of life lost between ages 15 and 65 could be attributed to a particular cause of death, taking into account competing mortality risks.

We analysed deaths by underlying cause using diagnostic categories of the ninth revision of the International Classification of Diseases. We examined a broad array of causes but report on the following ones found to be the most important in explaining death rate disparities: circulatory disease (390-459), cancer (140-
208), accidents (E800-E949), HIV/AIDS (042-044), homicide (E960-E969), infectious disease, pneumonia and influenza (001-041, 045-139, 480-487), and a separate category combining all remaining causes.

\section{Results}

SUMMARY MEASURES OF MORTALITY

African Americans nationwide or in local areas experience a substantial annualised rate of excess deaths relative to whites nationwide (see table 2). The magnitude of this excess is generally less for women than for men and in rural/ southern populations compared with urban/ northern ones. So too, African American men in the urban/northern locales experience RRs as high as 4.11 relative to whites nationwide, while African American women in the rural 
south experience RRs hovering around 1.75. Residents of poor rural/southern populations tend to do about as well, or in some cases, better than the black national average on either summary measure.

Most of the poor white populations exhibit excess mortality relative to whites nationwide, but this excess is generally smaller than for poor African American populations and there are specific instances of little or no excess in rural/southern poor white populations. The advantage to poor white women compared with poor white men is smaller than among poor African Americans. An urban/northernrural/southern divide is also suggested for poor whites, but it, too, is less dramatic than among poor African Americans. Generally members of the white populations fare substantially better than members of the black, yet, whites in the poor, urban/northern localities experience EDRs and RRs of roughly comparable size to those experienced by blacks nationwide or by residents of the African American poor rural/ southern areas.

CHANGES OVER TIME

Between 1980 and 1990 national death rates fell slightly more for whites than blacks and the gap between African Americans in poor local areas and whites nationwide increased in almost all cases. While excess mortality among the three urban/northern populations was roughly comparable in 1980, in 1990 residents of Harlem and Chicago did notably worse than residents of all other localities studied, including Central City Detroit. Among women in 1980, Harlem residents fared better than those in Chicago or Detroit, but by 1990 fared substantially worse than their counterparts in Detroit and comparably to those in Chicago. While evident in 1980, by 1990 the urban/rural divide had grown substantially among African American populations, because increases in excess deaths were smaller in the rural/ southern than in the urban/northern populations.

Changes in excess mortality between 1980 and 1990 were modest among the white study populations. Only the poor white population in Detroit clearly experienced an increase, while all of the remaining poor white populations remained stable or gained some improvement.

OTHER MORTALITY MEASURES

Almost all white men or women can expect to survive to age 45 and more than four fifths of white women and three quarters of white men can expect to survive to age 65 (see final three columns of table 2). Differences between 1980 and 1990 are slight. Residents of the poor white rural/southern populations face approximately the same probabilities of survival to or through middle age as whites nationwide, while those residing in Detroit, Cleveland, and Appalachian Kentucky fare worse in their probabilities of survival than whites nationwide. The age profiles of mortality in these three white populations are comparable to blacks nationwide and blacks residing in rural/southern study areas.
Residents of the African American urban/ northern populations fare the worst. Men face lower probabilities of survival to age 45 than those in poor white populations; sometimes they are less likely to survive to age 45 than white men are to survive to age 65 . The chances of survival to age 65 for men in poor, African American urban/northern populations are never more than fifty fifty. Women residents of these localities face only about a two thirds chance of survival to age 65 . Between 1980 and 1990, residents of Harlem and Chicago's south side witnessed notable decreases in their probability of survival to or through middle age.

Variation across populations in the average number of years of life lost (YOLL) between ages 15 and 65 is pronounced. Blacks, men, and urban residents lose more years of life than others. Among the African American local populations, the differential between urban and rural dwellers grew between 1980 and 1990. Residents of Harlem and Chicago's south side experienced especially large increases in average years of life lost over this time period. By 1990, African American men in these localities experienced an average of over 11 years of life lost, almost twice the number for blacks nationwide and almost four times the number for whites. While the absolute number of YOLL for women residents of Harlem or Chicago were lower, the excess compared with blacks or whites nationwide was of similar proportion.

CAUSES OF EXCESS MORTALITY

Decompositions of excess death rates show circulatory diseases to be important contributors to excess mortality in every poor population (see table 3). They constitute the leading cause of excess death in both years for men and women in all localities, except for Harlem men, often outpacing other contributors to excess deaths by a wide margin - an order of magnitude in some localities. In 1980, for Harlem men, excess deaths attributable to homicide exceed those resulting from to circulatory diseases; in 1990 circulatory disease deaths increased sufficiently to surpass those attributable to homicide, but are exceeded by AIDS deaths. For Harlem women in 1990, AIDS became the second leading cause of excess deaths. In Chicago, AIDS deaths to men are notable in 1990, but account for a much smaller proportion of the total excess than in Harlem. Elsewhere, AIDS deaths are not particularly important contributors to excess mortality.

For women in the poor populations, African American or white, homicide deaths never contribute more than $11 \%$ of the total excess deaths and, in most areas, contribute between zero and $5 \%$. Neither does homicide contribute to excess deaths of men in the white populations in North Carolina, Alabama or Louisiana. For men in all other populations, white or African American, homicide does contribute to excess mortality. Among African American men in Harlem, Chicago, Detroit and Louisiana, the contribution is sizeable, accounting for at least $20 \%$ of excess deaths in each of those 
Table 3 Causes of excess mortality among residents of selected populations, ages 15 to 64, 1980 and 1990

\begin{tabular}{|c|c|c|c|c|c|c|c|c|}
\hline & \multirow[b]{2}{*}{ Year } & \multicolumn{7}{|c|}{ National death rate per 100000 in white men } \\
\hline & & $\begin{array}{l}\text { Circulatory } \\
\text { disease }\end{array}$ & Cancer & Accident & Homicide & $H I V$ & $\begin{array}{l}\text { Infect/pneu/ } \\
\text { influenza }\end{array}$ & Other \\
\hline & 1980 & 177 & 108 & 72 & 14 & 0 & 9 & 97 \\
\hline & 1990 & 123 & 103 & 54 & 12 & 23 & 11 & 92 \\
\hline & \multicolumn{8}{|c|}{ Number of excess deaths per 100000 (age standardised) } \\
\hline \multicolumn{9}{|c|}{ ( } \\
\hline \multirow[t]{2}{*}{ United States } & 1980 & 92 & 57 & 9 & 73 & 0 & 20 & 82 \\
\hline & 1990 & 95 & 61 & 11 & 73 & 38 & 23 & 72 \\
\hline \multirow{2}{*}{ Harlem } & 1980 & 95 & 66 & -50 & 175 & 0 & 39 & 370 \\
\hline & 1990 & 205 & 118 & 20 & 175 & 296 & 150 & 332 \\
\hline \multirow[t]{2}{*}{ Central City Detroit } & 1980 & 189 & 69 & 2 & 176 & 0 & 39 & 231 \\
\hline & 1990 & 192 & 76 & -2 & 187 & 38 & 37 & 217 \\
\hline \multirow{2}{*}{ South Side Chicago } & 1980 & 315 & 152 & -4 & 212 & 0 & 45 & 235 \\
\hline & 1990 & 310 & 168 & 109 & 241 & 79 & 82 & 308 \\
\hline \multirow{2}{*}{ Delta Louisiana } & 1980 & 105 & 14 & 37 & 66 & 0 & 13 & 4 \\
\hline & 1990 & 168 & 88 & 52 & 37 & -10 & 8 & 49 \\
\hline \multirow{2}{*}{ Black Belt Alabama } & 1980 & 125 & 5 & 67 & 41 & 0 & 19 & 57 \\
\hline & 1990 & 114 & 37 & 83 & 32 & -8 & 10 & 69 \\
\hline \multirow{2}{*}{ East North Carolina } & 1980 & 163 & 79 & 35 & 36 & 0 & 35 & 98 \\
\hline & 1990 & 169 & 97 & 39 & 37 & 7 & 30 & 109 \\
\hline \multicolumn{9}{|l|}{ White men } \\
\hline Cleveland & 1980 & 165 & 55 & 21 & 56 & 0 & 9 & 104 \\
\hline & 1990 & 138 & 52 & 13 & 18 & 21 & -3 & 63 \\
\hline Detroit & 1980 & 118 & 21 & -4 & 27 & 0 & 5 & 84 \\
\hline & 1990 & 138 & 56 & 7 & 62 & -1 & 18 & 142 \\
\hline Appalachian Kentucky & 1980 & 78 & 44 & 82 & 49 & 0 & 6 & 26 \\
\hline & 1990 & 51 & 25 & 58 & 23 & -20 & 1 & 20 \\
\hline South Central Louisiana & 1980 & 38 & 17 & 55 & -5 & 0 & 0 & 7 \\
\hline & 1990 & 52 & 23 & 29 & -5 & -5 & 3 & -15 \\
\hline Northeast Alabama & 1980 & 31 & 4 & 30 & -1 & 0 & -2 & 4 \\
\hline & 1990 & 64 & 19 & 26 & 1 & -15 & -1 & 35 \\
\hline West North Carolina & 1980 & 19 & -16 & 11 & -2 & 0 & 5 & 10 \\
\hline & 1990 & 1 & -15 & 17 & -2 & -22 & -3 & 2 \\
\hline & & Nationaldea & ateper 100 & Dinwhitewon & & & & \\
\hline & Year & $\begin{array}{l}\text { Circulatory } \\
\text { disease }\end{array}$ & Cancer & Accident & Homicide & $H I V$ & $\begin{array}{l}\text { Infect/pneu/ } \\
\text { influenza }\end{array}$ & Other \\
\hline & 1980 & 70 & 96 & 21 & 4 & 0 & 6 & 55 \\
\hline & 1990 & 52 & 93 & 18 & 3 & 2 & 6 & 50 \\
\hline & Numbe & of excess death & er 10000 & age standara & & & & \\
\hline Black women & & & & & & & & \\
\hline United States & 1980 & 106 & 28 & 0 & 13 & 0 & 10 & 60 \\
\hline & 1990 & 89 & 32 & 2 & 12 & 13 & 14 & 53 \\
\hline Harlem & 1980 & 97 & 24 & -11 & 29 & 0 & 23 & 161 \\
\hline & 1990 & 137 & 53 & 2 & 20 & 99 & 72 & 152 \\
\hline Central City Detroit & 1980 & 146 & 49 & 3 & 34 & 0 & 16 & 130 \\
\hline & 1990 & 146 & 39 & -2 & 40 & 15 & 20 & 97 \\
\hline South Side Chicago & 1980 & 214 & 97 & -4 & 26 & 0 & 16 & 92 \\
\hline & 1990 & 193 & 79 & 22 & 41 & 10 & 43 & 181 \\
\hline Delta Louisiana & 1980 & 114 & 15 & 1 & 16 & 0 & 8 & 33 \\
\hline & 1990 & 152 & 23 & 17 & 4 & 1 & 5 & 46 \\
\hline Black Belt Alabama & 1980 & 74 & -9 & 14 & 12 & 0 & 1 & 71 \\
\hline & 1990 & 117 & 8 & 12 & 12 & 3 & 8 & 40 \\
\hline East North Carolina & 1980 & 92 & 10 & 10 & 6 & 0 & 17 & 52 \\
\hline & 1990 & 101 & 21 & 3 & 6 & 4 & 13 & 49 \\
\hline White women & & & & & & & & \\
\hline Cleveland & 1980 & 87 & 38 & 2 & 14 & 0 & 8 & 63 \\
\hline & 1990 & 72 & 33 & 4 & 4 & -2 & 1 & 35 \\
\hline Detroit & 1980 & 47 & 32 & -3 & 3 & 0 & 1 & 27 \\
\hline & 1990 & 93 & 30 & 0 & 12 & 2 & 7 & 59 \\
\hline Appalachian Kentucky & 1980 & 45 & 9 & 1 & 7 & 0 & 4 & 18 \\
\hline & 1990 & 40 & 20 & 17 & 4 & -2 & 1 & 7 \\
\hline South Central Louisiana & 1980 & 32 & -2 & 10 & -1 & 0 & 6 & 11 \\
\hline & 1990 & 20 & 16 & 8 & -1 & -2 & -4 & -5 \\
\hline Northeast Alabama & 1980 & 9 & -13 & 9 & 0 & 0 & -3 & -1 \\
\hline & 1990 & 41 & -4 & 20 & 3 & -2 & 0 & 0 \\
\hline West North Carolina & 1980 & -1 & -18 & 2 & 1 & 0 & 1 & -9 \\
\hline & 1990 & -4 & -26 & 2 & 0 & -2 & 1 & -3 \\
\hline
\end{tabular}

populations in 1980. However, between 1980 and 1990 the absolute numbers of homicide deaths among men remained relatively stable while the percentage of excess deaths accounted for by homicide witnessed notable declines. In Harlem, homicide deaths decreased from $25 \%$ of excess deaths to men in 1980 to $14 \%$ in 1990 ; in Chicago, from $22 \%$ to $19 \%$; and in the Delta Louisiana population, from over a quarter (28\%) in 1980 to only $10 \%$ in 1990. Among black men in Detroit, the percentage of excess deaths attributable to homicide among men stayed stable at $25 \%$ in both time periods, while white men in Detroit are the only group to experience an increase in both absolute number and percentage of excess deaths accounted for by homicide.

Between 1980 and 1990, unlike excess deaths attributable to homicide, deaths to most other causes rose in urban/northern poor African 


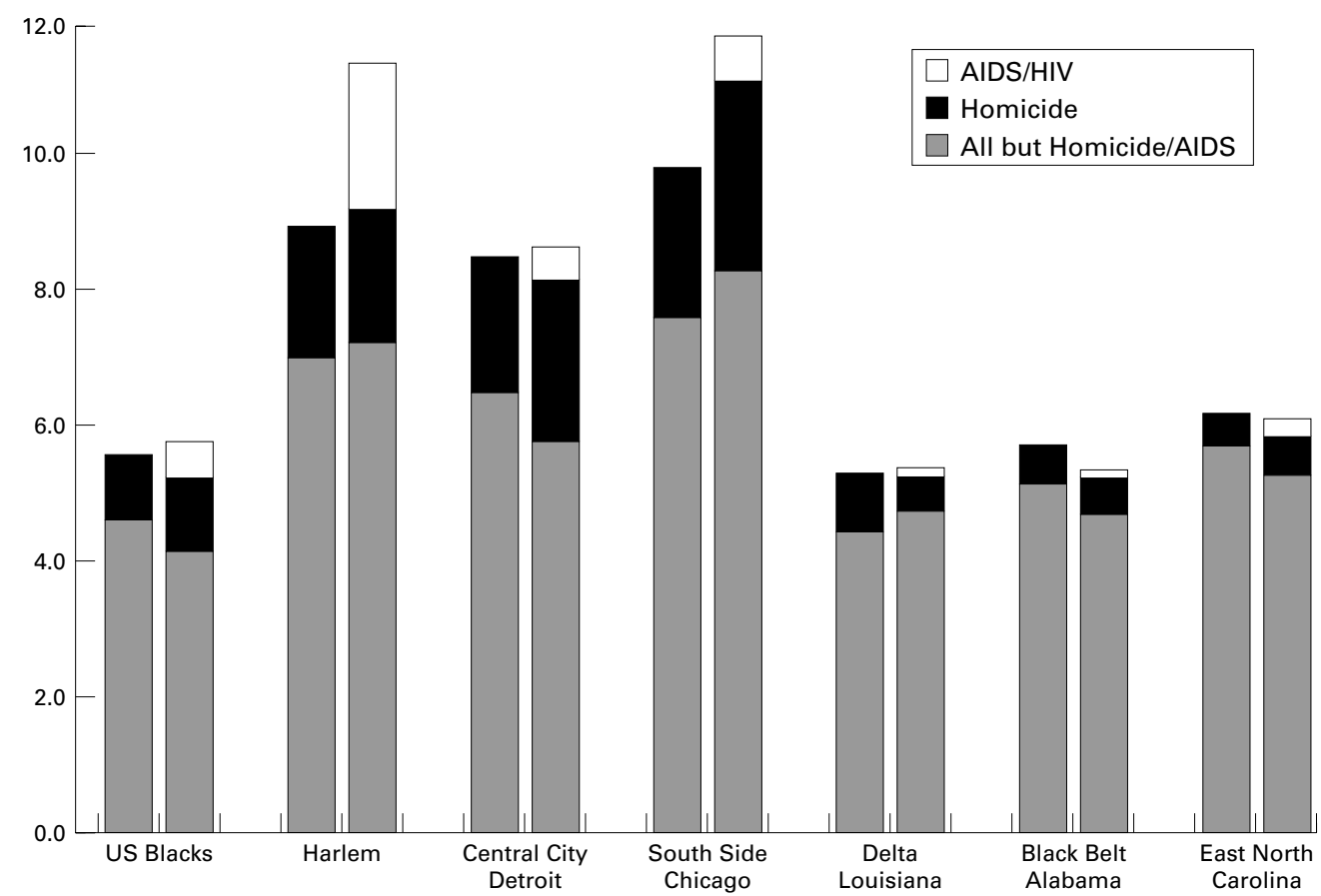

Figure 1 Years of life lost by cause, 1980 and 1990, black men.

American localities. In addition to AIDS, excess deaths attributable to circulatory deaths, cancer deaths, accidental deaths, and deaths attributable to infections rose in Harlem, often dramatically. For example, cancer deaths doubled for men or women, while excess circulatory disease deaths doubled for men and rose by $40 \%$ for women. African Americans in Chicago and Detroit also experienced increases in several causes of death.

Accidents contribute notably to excess deaths in rural/southern populations, African American or white, and are the leading cause of excess deaths among men in Appalachian

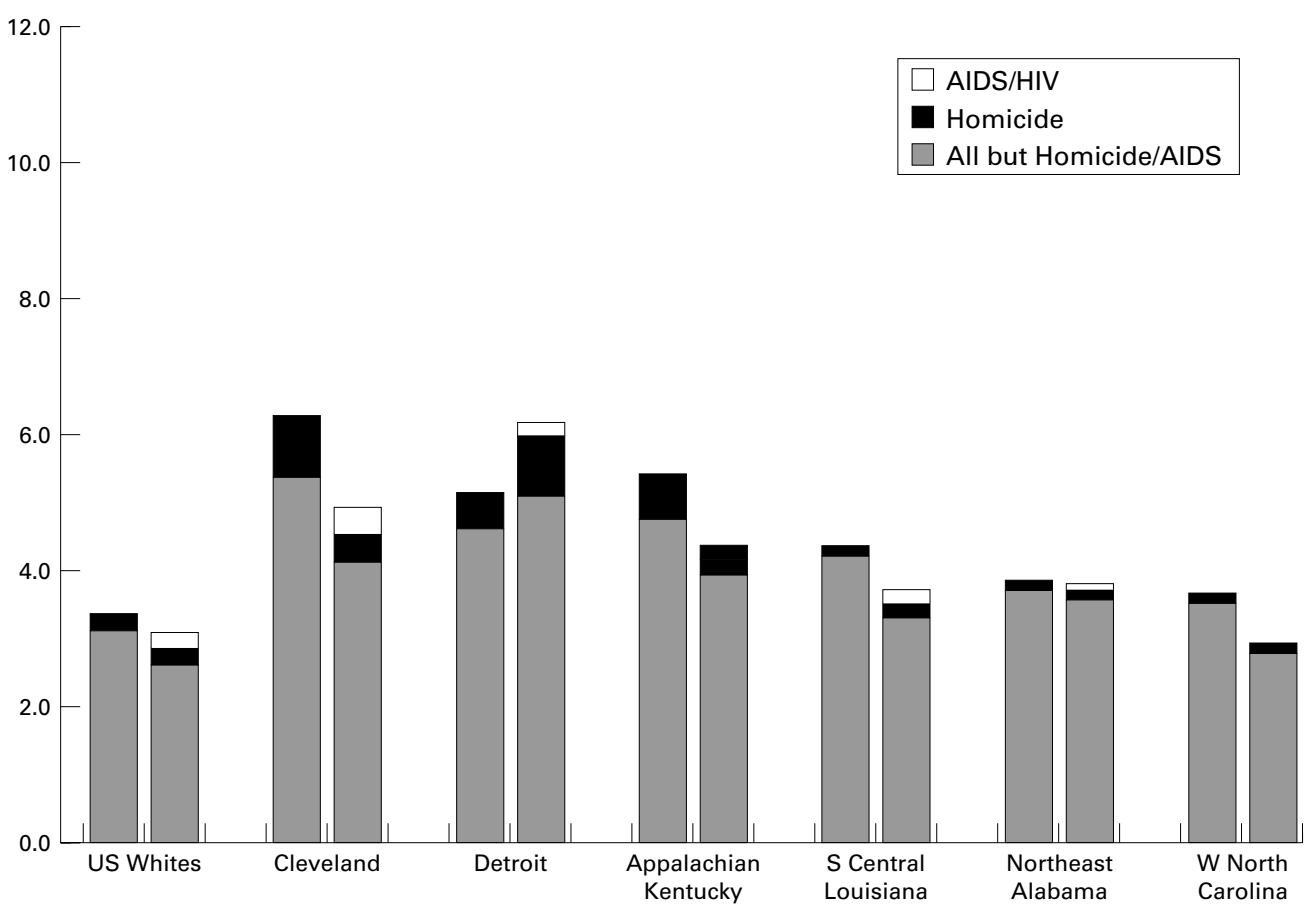

Kentucky in both years. They are of lesser importance in the urban/northern populations, although Harlem and Chicago residents experienced increases in the number and proportion of excess deaths attributable to accidents between 1980 and 1990. For example, among Chicago men, accidents did not contribute to excess deaths in 1980, but by 1990 contributed 109 or $9 \%$ of excess deaths.

AIDS or homicide deaths disproportionately kill people earlier in their adult lives than other important causes such as circulatory diseases or cancers. Thus, these causes of death might take a large toll on the younger members of the

Figure 2 Years of life lost by cause, 1980 and 1990, white men. 


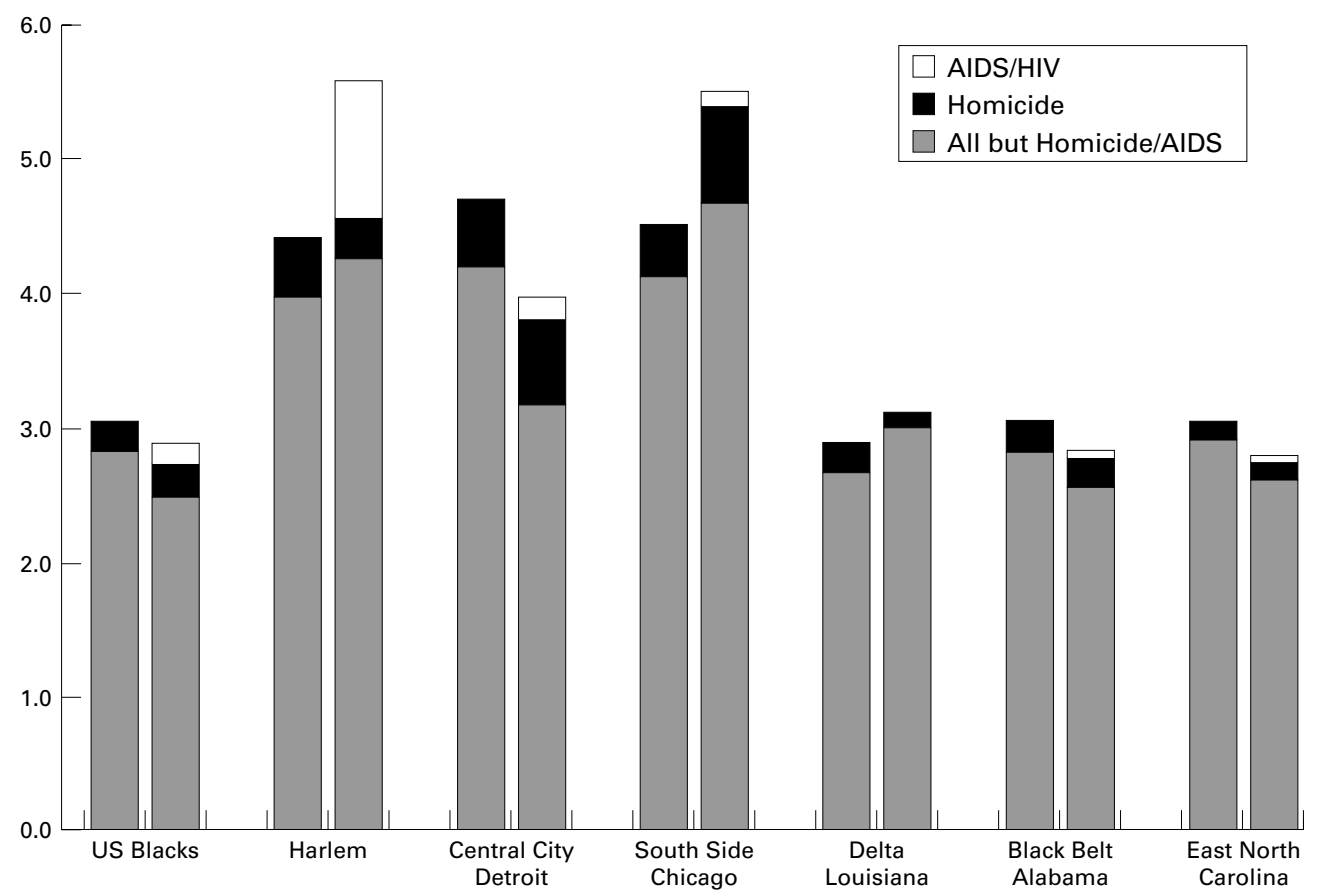

Figure 3 Years of life lost by cause, 1980 and 1990, black women.

15 to 65 year-old age group under study. To gauge this, the bar graphs in figures $1-4$ subdivide the average years of life lost according to the fraction attributable to AIDS, homicide, and all other causes. Using the average years of life lost as the denominator highlights the contribution of AIDS or homicide to mortality in the younger part of the age distribution under study, because those who die at younger ages (that is, those who are more likely to die from AIDS or homicide) will contribute more to the average years of life lost than those who die at older ages (that is, those who are more likely to die from circulatory disease or cancer).
Even with this "magnification" of the importance of deaths attributable to AIDS or homicide, these causes alone do not go far in explaining the general observed mortality differences (that is, those by race, sex, poverty, or region, all of which, while reduced, would have remained substantial in the absence of AIDS or homicide deaths). However, AIDs or homicide deaths do account for the increased number of YOLL between 1980 and 1990 for black men nationwide and in Detroit. In several additional localities, improvements over the decade would have been more notable in their absence. Of greatest impact, most of the

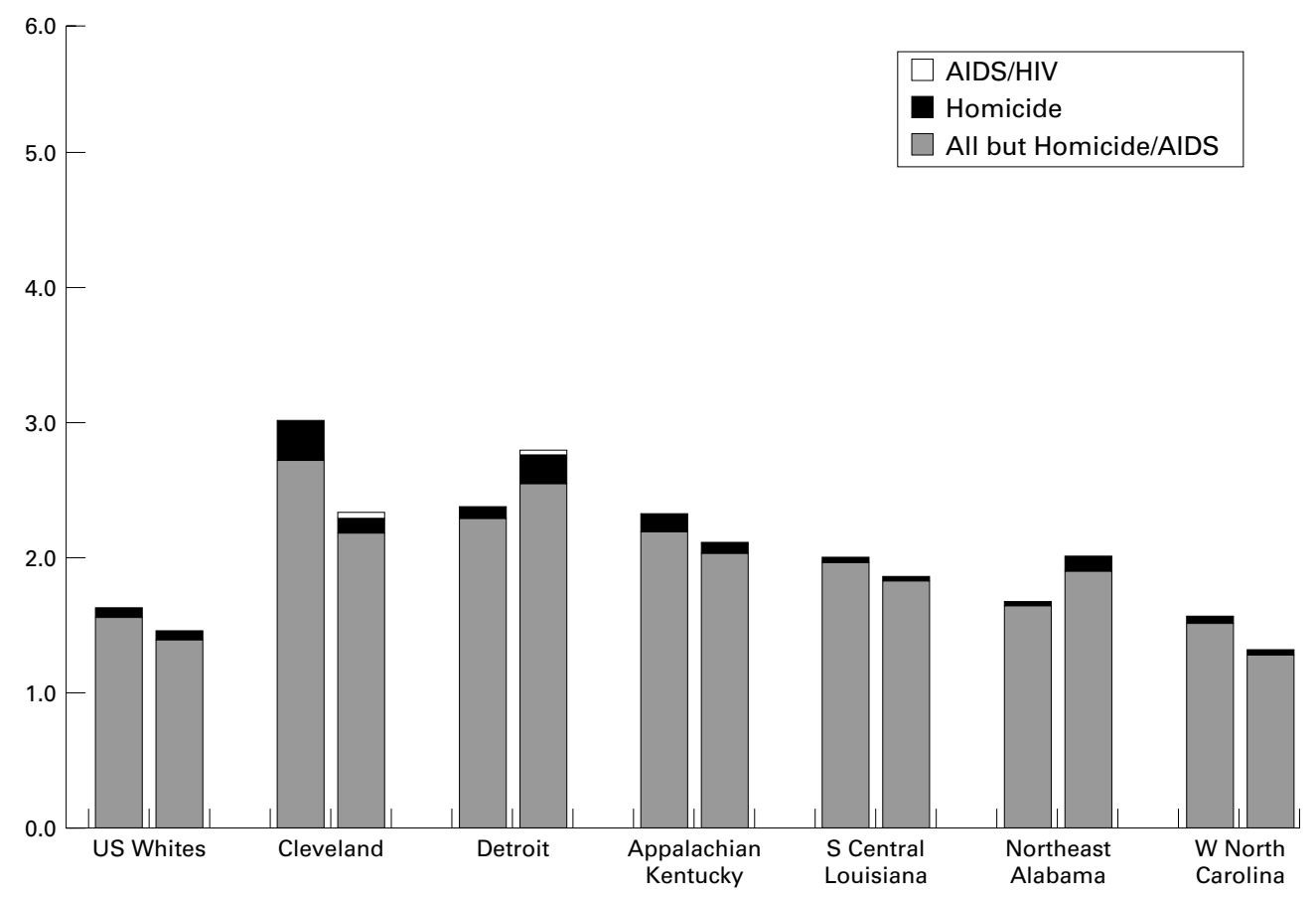

Figure 4 Years of life lost by cause, 1980 and 1990, white women. 
substantial increase in YOLL in Harlem between 1980 and 1990 can be accounted for by deaths to these two causes. In the absence of the AIDs epidemic, YOLL for Harlem men might well have remained fairly stable over this decade and would have been intermediate between Detroit and Chicago in 1990 as it was in 1980 .

\section{Discussion}

Poor local populations pay a heavy toll in the loss of potentially productive members in their prime of life. The size of this toll varies across disadvantaged populations and between men and women in the same population. African American men residing in persistently impoverished urban/northern localities face the most severely disadvantageous mortality profiles in their young adult through middle ages. This disadvantage became increasingly substantial over the 1980s.

Unlike those in urban/northern areas, rural/ southern poor populations tend to experience little excess mortality relative to their respective sex and race specific national averages. There is clear evidence of this urban/northern-rural/ southern divide among the African American populations, especially in 1990, and more modest evidence of it among whites. The rural/ southern white populations tend to be better off economically than the urban/northern white populations, perhaps, explaining their mortality advantage. However, whites in Appalachian Kentucky were from the poorest white population, yet their mortality rates were lower than exhibited by poor white populations in the north, including the 1980 Detroit white population that had a poverty rate only somewhat higher than the white national average and one third the rate of the Kentucky population. Indeed, white residents of Cleveland and Detroit had mortality profiles roughly comparable to those of the rural/southern African American populations or to blacks nationwide despite having dramatically lower poverty rates.

For African Americans, the rural/southern populations tend to be as socioeconomically disadvantaged as (or, in some cases, more disadvantaged than) the northern/urban populations. Yet, as a group, they have substantially better mortality profiles than their counterparts in northern cities. These differences persist even after adjustment for cost of living differences. $^{27} 28$ Despite their high poverty rates, the rural/southern African American populations experience mortality at comparable levels to the black national average and to the white urban poor populations.

The magnitude of the rural mortality advantage between poor populations far exceeds that estimated in analyses of national data sets that average across rural or urban populations. Such studies that find a rural advantage typically estimate it to be $2 \%-10 \% .^{8}{ }^{15-19}$ Sex specific ratios of annualised death rates for specific rural compared with urban populations in this study yield a rural mortality advantage in 1990 that is never less than $20 \%$ and often exceeds $100 \%$. These large differences suggest an important interaction be- tween poverty, race, and residence that has not been previously noted. Among the poor, generally, and the African American poor, in particular, large gains in the probability of survival through middle age are associated with rural residence.

This important rural advantage is largely accounted for by a combination of lower rates of excess deaths attributable to circulatory diseases, cancer, and, in men, homicide, as well as a narrowing of the gap in accidental deaths that favour urban populations. As of 1990, deaths attributable to infectious disease played a relatively smaller part than might have been predicted in explaining growth in excess mortality in urban compared with rural areas. Further systematic study is warranted to illuminate the ultimate social or epidemiological processes that trigger these disparities. High levels of mortality in urban/northern central cities may be secondary to deterioration of urban infrastructure and city services. ${ }^{29}$ Alternatively (or additionally) members of poor rural/southern communities might enjoy protections against deteriorating health conferred, for example, as some have speculated, by a greater degree of social cohesion ${ }^{30}$ or a less sedentary or stressful lifestyle. ${ }^{16} 19$

We did not find a uniform level or even direction of change over time among the study populations. National studies suggest social disparities in mortality have been growing among this age group. ${ }^{31-33}$ This study is not designed to answer that question on a national level, however, our findings suggest this is true in some poor localities but not others. Among the white populations, only Detroit experienced an increase. Between 1980 and 1990 the Detroit population declined in size and in level of economic well being. This selective out migration of economically better off residents might explain its worsening mortality profile. The picture for African American women was varied. Nationally and in Detroit, North Carolina, and Alabama they experienced declines in excess mortality over the decade, while in Harlem, Chicago, and Louisiana increases were evident. African American men nationwide and in urban/northern localities experienced mortality increases. Rural/southern men did not. These findings offer clues about where or why any broader growth in social inequalities in mortality may be occurring.

The contribution of homicide to changes in excess deaths between 1980 and 1990 is unremarkable. Differential experience with AIDS is important, although not fully explanatory. As of the early 1990s, AIDS seems to have played little part in excess mortality in poor populations outside of specific localities. Whether the epidemic remained contained in those areas requires further study. Harlem's experience suggests how devastating HIV disease can be for a local community. In one decade, it accounted for an additional 300 excess deaths per year among men and increased their average YOLL by more than two years. Excess deaths to a wide range of chronic and infectious diseases, as well as to accidents, play a larger 
part than AIDS or homicide in explaining mortality increases over the decade.

The consistencies found across a diverse range of populations create some confidence that they represent underlying regularities that may be applicable to general categories of poor populations across the United States (for example, urban/northern compared with rural/ southern). Yet, data requirements place limitations on our analysis. Because of population size requirements, we cannot distinguish between the effects attributable to being southern or rural and between being northern or urban. Vital statistics data were virtually never geocoded before 1980, ruling out a longer time series. Including disadvantaged representatives of other ethnic groups was not feasible (see footnote).

A complicated interpretive issue is that race and socioeconomic position are confounded in this analysis. The fact that we could not identify white populations as poor as the poorest black populations in the United States is itself suggestive of the relative importance of race in the United States as explanatory of inequalities in health, even if this social category (race) operates, in part, through economic characteristics to exert its effect on mortality. ${ }^{34}$ However, while deeper poverty might contribute to the worse mortality experience of African Americans relative to whites, it cannot explain the specific instances where economically better off white populations fare as poorly as some more economically disadvantaged black. In addition, the heterogeneity among the African American populations studied is not so neatly summarised.

In summary, important differences exist among and within persistently impoverished populations by race, sex, geographical location, and time period in the degree to which their poverty translates into excess mortality. Some mortality differences are evident by age 45 . More generally, mortality differences intensify between ages 45 and 65, resulting, in large part, from circulatory diseases and cancer. These findings support the broadening of social epidemiological inquiry and health promotion campaigns to focus on (1) characteristics of geographical areas and (2) the physiological effects of the psychosocial stresses of daily living experienced by the disadvantaged in the context of the specific localities they inhabit. ${ }^{35-37}$ Our findings document a poignant dimension of social disparities in health - that young people in some US communities cannot expect to survive through middle adulthood. While highly publicised

For example, no Native American population is of sufficient size for fine grained mortality analyses among young and middle aged adults. Several problems are associated with attempting to study Latino ethnic populations in this way. These include: the inability to correct for census underenumeration; underreporting of Hispanic ethnicity on death certificates; and selective migration based on health status among Mexican or Puerto Rican populations - both a "healthy migrant" effect (the migration to the mainland United States of the more healthy) and a "salmon bias" (going back to one's birthplace after becoming ill). causes of premature death such as AIDS and homicide do contribute to this, they do so by adding to social disparities in mortality experience that are already substantial and result primarily from chronic disease in young and middle adulthood. This process indicating early health deterioration, evident before AIDs (in 1980) and in communities where, even in 1990 , AIDS is not prevalent, may reverberate throughout communities. Community members pay a price in the loss of productive members and, perhaps, in expanded responsibility for dependent care falling to the young and middle aged adults who remain. This responsibility, itself, may exacerbate the risk of disease.

We are indebted to Reynolds Farley and two anonymous reviewers for helpful comments; Lisa Neidert for data consultation; Cathy Sun and Patricia B Burns for programming tion; Cathy Sun and Patricia B Burns for programming Judy Mullin for help with production of the manuscript.

Funding: this work was supported by grants from the Centers Funding: this work was supported by grants from the Centers for Disease Control (grant \#U83/CCU51249) and the William was a Robert Wood Johnson Foundation Investigator in Health was a R
Policy.

Policy.
Conflicts of interest: none.

\section{Appendix}

STUDY POPULATIONS

African American

Harlem

African Americans living in the Central Harlem Health Center District.

South Side Chicago

African Americans living in the Near South Side, Douglas, Oakland, Fuller Park, Grand Boulevard and Washington Park community areas.

Central City Detroit

African Americans living in the Central, University, Central Business District, Foch, Jefferson-Mack, Airport, St. Jean, Chene, and Jeffries subcommunities of Detroit.

East North Carolina

African Americans living in Pitt, Northampton, Halifax and Edgecombe counties.

\section{Black Belt Alabama}

African Americans living in rural counties in and around the Black Belt region including Dallas, Fayette, Greene, Bibb, Sumter, Hale, Lamar, Marengo, Marion, Perry, and Pickens counties.

Delta Louisiana

African Americans living in the Caldwell, East Carroll, Franklin, Jackson, Madison, Morehouse, Richland, Tensas, Union, West Carroll, Avoyelles, Catahoula, Concordia, Grant, La Salle, Vernon, and Winn parishes.

\section{White}

Cleveland

Whites living in the west-central area of Cleveland.

Detroit

Whites living in subcommunities on the northeastern and southern periphery of Detroit, including Delray, Clark Park, Chadsey, Condon, Springwells, Jeffries, State Fair, Burbank, Denby, Finney, Mt. Olivet, Grant, Davison, Pershing, and Nolan. 
Appalachia

Whites living in the Appalachian Kentucky counties of Clay, Jackson, Knox, Lee, Leslie, Owsley, Rockcastle, and Wolfe.

West North Carolina

Whites living in Alleghany, Ashe, Avery, Mitchell, Watauga, Wilkes, and Yancey counties.

Northeast Alabama

Whites living in DeKalb, Jackson, and Marshall counties.

South Central Louisiana

Whites living in Acadia and Vermilion parishes.

1 Geronimus AT. Black/white differences in the relationship of maternal age to birthweight: A population-based test of the weathering hypothesis. Soc Sci Med 1996;42:589-97.

2 Davey Smith G, Hart C, Blane D, et al. Lifetime socioeconomic position and mortality: prospective observational study. BMF 1997;314:547-52.

3 Stack CB, Burton LM. Kinscripts. Fournal of Comparative Family Studies 1993;24:157-69.

4 Chatters LM, Jayakody R. Intergenerational support within African American families. In: Bengtson VL, Schaie KW, Burton LM, eds. Adult intergenerational relations: effects of societal change. New York: Springer Publishing, 1995:97118.

Aeronimus AT. The weathering hypothesis and the health of African American women and infants: Evidence and speculations. Ethn Dis 1992;2:207-21.

6 Sorlie P, Rogot E, Anderson R. et al. Black-white mortality differences by family income. Lancet 1992;340:346-50.

7 House JS, Lepkowski JM, Kinney AM, et al. 1994. The social stratification of aging and health. F Health Soc Behav 1994; 35:213-34

8 Elo IT, Preston SH. Educational differentials in mortality: United States, 1979-85. Soc Sci Med 1996;42:47-57.

9 McCord C, Freeman HP. Excess mortality in Harlem. $N$ Engl f Med 1990;322:173-7.

10 Geronimus, AT, Bound, J. Waidmann, TA, et al. Excess mortality among blacks and whites in the United States. $N$ Engl f Med 1996;335:1552-8.

11 Guest AM, Almgren G, Hussey JM. The ecology of race and socioeconomic distress: infant and working-age mortality in Chicago. Demography 1998;35:23-34.

12 Pariante CM, Carpiniello B, Orru MG, et al. Chronic caregiving stress alters peripheral blood immune caregiving stress alters peripheral blood immune parameters: The role of age and
Psychother Psychosom 1997;66:199-207.

13 Fox JP, Hall CE, Elveback LR. Epidemiology: man and disease. New York: Macmillan, 1970.

14 Wright JS, Champagne F, Dever GEA, et al. A comparative analysis of rural and urban mortality in Georgia, 1979. Am f Prev Med 1985;1:22-9.

15 Kitagawa EM, Hauser PM. Differential mortality in the United States: A study in socioeconomic epidemiology. Cambridge, MA: Harvard University Press, 1973.

16 Pendleton BF, Chang HC. Ecological and social differentials in mortality: inequalities by metropolitan- nonmetropolitan residency and racial composition. Sociol Focus 1979;12:21-35.

17 Miller MK, Stokes CS, Clifford WB. A comparison of the rural-urban mortality differential for deaths from all causes, cardiovascular disease and cancer. 7 Rural Health 1987;3:23-34.

18 Office of Technology Assessment, U.S. Congress (OTA). Health care in rural America. Washington DC: Government Printing, 1990.

19 Schneider D, Greenberg MR. Death rates in rural America 1939-1981: convergence and poverty. In: Gesler WM, Ricketts TC, eds. Health in rural North America: the geography of health care services and delivery. New Brunswick: Rutgers University Press, 1992.

20 Wilson WJ. The truly disadvantaged. Chicago: University of Chicago Press, 1987

21 Brown LD. The changing policies and politics of urban health. Health Aff (Millwood) 1993;12:233-6.

22 Kitagawa EM. Standardized comparisons in population research. Demography 1964;1:296-315.

23 Chiang CL. The life table and its applications. Malabar, FL: Robert E Krieger Publishing, 1984.

24 Shyrock HS, Siegel J. The methods and materials of demography. Washington DC: Government Printing Office, 1975.

25 Smith DP. Formal demography. New York: Plenum Press, 1992.

26 Chiang CL. A stochastic study of the life table and its applications: III. The follow-up study with the consideration of competing risks. Biometrics 1961;17: 57-78.

27 Kokoski MA, Cardiff P, Moulton B. Interarea price indices for consumer goods and services: An hedonic approach using CPI data. BLS Working Paper No. 256. Washington, DC: Bureau of Labor Statistics, 1994.

28 Bureau of Labor Statistics. Urban family budgets and comparative indexes for selected urban areas. USDL 82-139. Washington DC: US Department of Labor, 1982

29 Wallace R, Wallace D. Origins of public health collapse in New York City: the dynamics of planned shrinkage, contagious urban decay and social disintegration. Bull NY Acad Med 1990;66:391-434.

30 House JS, Landis KR, Umberson D. Social relationships and health. Science 1988;241:540-5.

31 Feldman JJ, Makuc DM, Kleinman JC, et al. National trends n eduational differentials in mortality. Am 7 Epidemiol 1989;129:919-33.

32 Pappas G, Queen S, Hadden W, et al. The increasing disparity in mortality between socioeconomic groups in the United States, 1960 and 1986. New Engl f Med 1993;329: 103-9.

33 Preston SH, Elo IT. Are educational differentials in adult mortality increasing in the United States? fournal of Aging and Health 1995;7:476-96.

34 Cooper R, David R.The biological concept of race and its application in public health and epidemiology. 7 Health Polit Policy Law 1986; 11:97-116.

35 Davey Smith G, Hart C, Watt G, et al. Individual social class, area-based deprivation, cardiovascular disease risk factors, and mortality: The Renfrew and Paisley study. $\mathcal{f}$ Epidemiol Community Health 1998;52:399-405.

36 James SA. John Henryism and the health of AfricanAmericans. Cult Med Psychiatry 1994;18:163-82.

37 Wilkinson RG. Health inequalities: relative or absolute material standards? BMf 1997;314:591-5. 